\title{
Nebulised therapy in acute severe bronchiolitis in infancy
}

\author{
G M STOKES, A D MILNER, I G C HODGES, R L HENRY, AND M C ELPHICK \\ Department of Child Health, University of Nottingham, University Hospital, Queen's Medical Centre, \\ Nottingham
}

SUMMARY We have measured total work of breathing before and after the inhalation of water, salbutamol, and ipratropium bromide, given as nebulised solutions, in 39 studies on 25 infants with acute, severe bronchiolitis. Twenty minutes after nebulised water, mean work of breathing per minute was increased by $4 \%$ and work per litre by $10 \%$ with 2 infants having significant improvement and 2 others showing deterioration. After salbutamol, mean work of breathing per minute showed a $22 \%$ increase and work per litre a $0.5 \%$ rise. The condition of only one child improved by $>25 \%$ after this drug. Ipratropium bromide led to significant improvement in 6 out of 15 studies and no corresponding deterioration. The group results showed a fall in work of breathing, $18 \%$ in work per minute and $16 \%$ in work per litre.

Although acute viral bronchiolitis is the most common lower respiratory tract infection in the first year of life, it has remained frustratingly resistant to treatment with drugs. Lung function tests on sedated infants in the convalescent phase have failed to demonstrate any benefit from nebulised isoprenaline, salbutamol, phenylephrine, or epinephrine. ${ }^{1-3}$ Other trials have been unable to show that antibiotics, corticosteroids, and recently, theophylline in any way influence the course of the disease. ${ }^{4-7}$

Despite this, many paediatricians continue to give bronchodilator drugs in the acute phase, claiming that results from trials carried out during convalescence cannot be extrapolated to the critical stage of the illness.

Objective measurements of lung function in the critical phase of bronchiolitis have not been possible since few infants will tolerate a face mask without sedation, and this is precluded in the presence of respiratory failure.

In order to overcome this problem, we have devised a new technique which allows us to study the total work of breathing in acutely sick infants without the need for sedation, using an inflated rubber jacket to measure tidal volume and a water-filled nasogastric tube to record oesophageal pressure. This system has been fully validated and used to collect information on the natural history of acute severe bronchiolitis. ${ }^{8} 9$

We therefore set out to study a group of babies in the critical phase of acute viral bronchiolitis to assess the therapeutic effects of 3 nebulised solutions: salbutamol, ipratropium bromide, and water, using this non-invasive technique to measure changes in total work of breathing. Salbutamol was chosen because it is widely used clinically, and because the results could be compared with previous reports of trials performed in the convalescent period. $^{1-3}$ Ipratropium bromide, an anti-cholinergic drug, is an atropine derivate which has minimal effects on secretions and heart rate. It was chosen on the grounds that previous studies have shown that, unlike $\beta_{2}$ stimulants, it is effective in relieving airways obstruction in some wheezy toddlers and babies. ${ }^{10} 11$ We included water, as mist therapy is still occasionally administered to children with acute bronchiolitis, and it was obviously important to distinguish the response to the physical property of a nebulised solution from that of active drugs.

\section{Methods}

Oesophageal pressures. Oesophageal (intrathoracic) pressure swings were obtained from a pressure transducer (Ormed Type 524) connected to a nasogastric tube (FG6) which had been passed for feeding. The tube was gently perfused with water and withdrawn from the stomach so that the tip lay 2-3 cm above the diaphragm. ${ }^{8}$ The resulting signals were relayed simultaneously to a 2-channel pen recorder (Ormed-Type MX212), a magnetic tape recorder (Tandberg TJR 115), and to an 'on line' computer (Commodore 32K PET, Series 2001). 
Tidal volumes. Tidal thoracic volumes were measured by a second pressure transducer (Pye Ether UP1) linked via tubing to a thin, rubber, inflated jacket, which encompassed the child's trunk and fitted snugly round the neck. The 1-2 $\mathrm{mm}$ pressure changes which occurred within the jacket as a result of respiration enabled tidal volumes to be measured. These volumes were calibrated by alternately injecting and withdrawing known volumes of air from the jacket via a syringe every 6-10 breaths, and measuring the change in end tidal baseline. These signals were also relayed to the pen and tape recorders and to the on line computer. Previous work has shown that measurements of tidal volume obtained in this way correlate closely $(r=0.98)$ with those measured simultaneously by a pneumotachograph system in a group of asymptomatic infants. ${ }^{8}$

Calculations of total work of breathing. On line oesophageal pressure and tidal thoracic volume signals were relayed through the analogue-to-digital converter into the computer. This information was sampled 30 times a second and used to construct pressure-volume loops. Total work of breathing was calculated from the sum of the area within the inspiratory and expiratory pressure-volume loops and the triangular area to the left of the line joining the end-tidal points (Fig. 1). The expiratory component of the pressure-volume loop was added to the inspiratory portion as we have found that babies produce positive pressures on expiration. ${ }^{9}$ These cannot be separated into true resistive and elastic components, as there is an inevitable phase shift between volume measured at the mouth and thoracic volume change as measured by the jacket or plethysmograph. However assessments of total work of breathing obtained using a pneumotachograph were only $4 \%$ greater than those using the jacket in a group of healthy babies, indicating that the

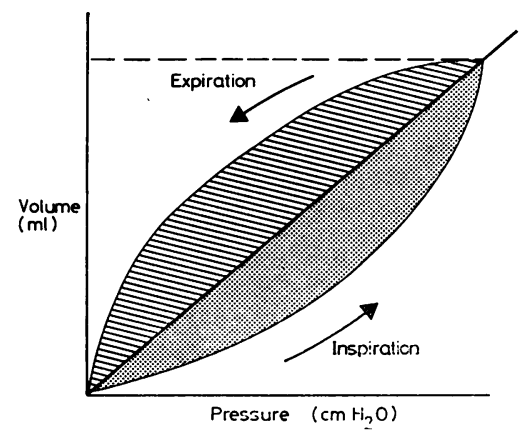

Fig. 1 Diagram of pressure volume loop from which calculations of work of breathing are made. tendencies to over-record elastic and under-record resistive work cancel each other out.

Preparatory study to ascertain the effect of sleep states on total work of breathing. Babies with acute severe bronchiolitis have been found to breathe erratically, inevitably introducing a degree of variability into measurements of work of breathing. We therefore considered it necessary to study the reproducibility of work of breathing measurements in quiet and rapid eye movement (REM) sleep. Preliminary work showed that the babies' spontaneous body movements when awake distorted the trace too much for reliable results to be obtained over more than a few breaths.

Forty-two 30-second recordings were collected on 12 infants (mean age 17 weeks) in the critical phase of acute bronchiolitis who were in REM sleep, as determined by rapid eye and intermittent body movements, allowing an average interval of 17.6 minutes (range 1 minute to 2 hours) between measurements in order to calculated the variability. A mean variation of $28.8 \%$ was found in work of breathing per minute and of $24.4 \%$ in work per litre. In a similar way 39 studies were made on 12 infants (mean age 12 weeks) in quiet sleep, with no visible eye or limb movements at an average interval of 18.9 (range 1 to 90 ) minutes. In this group the average variability fell to $12.8 \%$ for work per minute and $11.1 \%$ for work per litre.

We also compared the results obtained during quiet and REM sleep by analysing 32 recordings each of 30-seconds from babies whose sleep state varied. The results showed a wide scatter. Nevertheless, on average the work of breathing per minute and per litre was higher in REM sleep by $49.2 \%$ $(\mathrm{SD} \pm 64)$ and $17.9 \%(\mathrm{SD} \pm 30 \cdot 2)$ respectively. We therefore decided to carry out the definitive studies in quiet sleep and to regard a larger than $25 \%$ fall in work of breathing as a significant improvement.

\section{Patients}

We made 39 assessments on 25 infants who had a mean age of 17 (range 5-48) weeks, a mean birthweight of $2.85 \mathrm{~kg}$, and a mean weight on admission of $5 \cdot 4 \mathrm{~kg}$.

All the children were admitted during a respiratory syncytial virus epidemic and had been diagnosed as having acute bronchiolitis, based on the clinical findings of tachypnoea, hyperinflation, and diffuse crepitations. Respiratory syncytial virus was isolated in 15 infants. Sixteen babies had 1st- or 2nd-degree relatives with asthma, 2 with hay fever, and 2 with eczema. All needed nasogastric tubes to maintain hydration and nutrition. 


\section{Procedure}

Otrovine nasal drops were administered before the start of the study to clear the upper airways. Total work of breathing was calculated during an initial 30 -second period. The child then inhaled a 2-ml solution delivered to a face mask by a Sandoz paediatric nebuliser. The drug regimens used were salbutamol $5 \mathrm{mg}$, ipratropium bromide $250 \mu \mathrm{g}$, and water, and all were administered randomly and double-blind. All the assessments were made at a time that the babies were in quiet sleep.

\section{Results}

The initial measurements of total work of breathing were high. Mean work of breathing per litre was 13127 (range 6648-35 713) g/cm and mean work per minute 24027 (range 6769-145 742) g/cm. This represents an average 4-fold increase in the energy cost of breathing. ${ }^{9}$ There was no significant difference between the initial values in the three treatment groups.

Results for the work of breathing after the inhalations are shown in Figure 2a and b and in Table 1, and changes in other lung function parameters in Table 2. Although 2 infants showed a larger than $25 \%$ improvement after nebulised water, no change was seen in the group as a whole. In one who showed a $>25 \%$ deterioration, work per minute was $220 \%$ of the initial reading and work per litre $282 \%$ of initial.

After nebulised salbutamol there was effectively no change in work of breathing per litre $(0.5 \%$ increase) and a mean deterioration of $21.8 \%$ in work per minute with 4 infants showing a larger than $25 \%$ change. Coughing occurred in 6 babies during the inhalation of this drug.

Ipratropium bromide however produced a mean improvement of $18.2 \%$ in work of breathing per minute with 6 babies showing a larger than $25 \%$ change. The mean $16 \%$ fall in work of breathing per litre included 3 babies with a larger than $25 \%$ improvement. No child had a larger than $23 \%$ deterioration in work of breathing per minute or per litre after ipratropium bromide.
Table 2 Changes in lung function parameters, expressed as a percentage of baseline, 20 minutes after nebulised therapy

\begin{tabular}{|c|c|c|c|c|}
\hline Therapy & $\begin{array}{l}\text { Oesophageal } \\
\text { pressure }\end{array}$ & $\begin{array}{l}\text { Tidal } \\
\text { volume }\end{array}$ & $\begin{array}{l}\text { Respiratory } \\
\text { rate }\end{array}$ & $\begin{array}{c}\text { Minute } \\
\text { volume }\end{array}$ \\
\hline $\begin{array}{l}\text { Water } \\
\text { Salbutamol } \\
\text { Ipratropium }\end{array}$ & $\begin{array}{r}98 \cdot 4 \\
102 \cdot 6\end{array}$ & $\begin{array}{r}98 \cdot 8 \\
111 \cdot 9\end{array}$ & $\begin{array}{l}101 \cdot 3 \\
110 \cdot 9\end{array}$ & $\begin{array}{r}82 \cdot 3 \\
123 \cdot 7\end{array}$ \\
\hline bromide & 83 & $95 \cdot 3$ & $102 \cdot 2$ & $97 \cdot 7$ \\
\hline
\end{tabular}

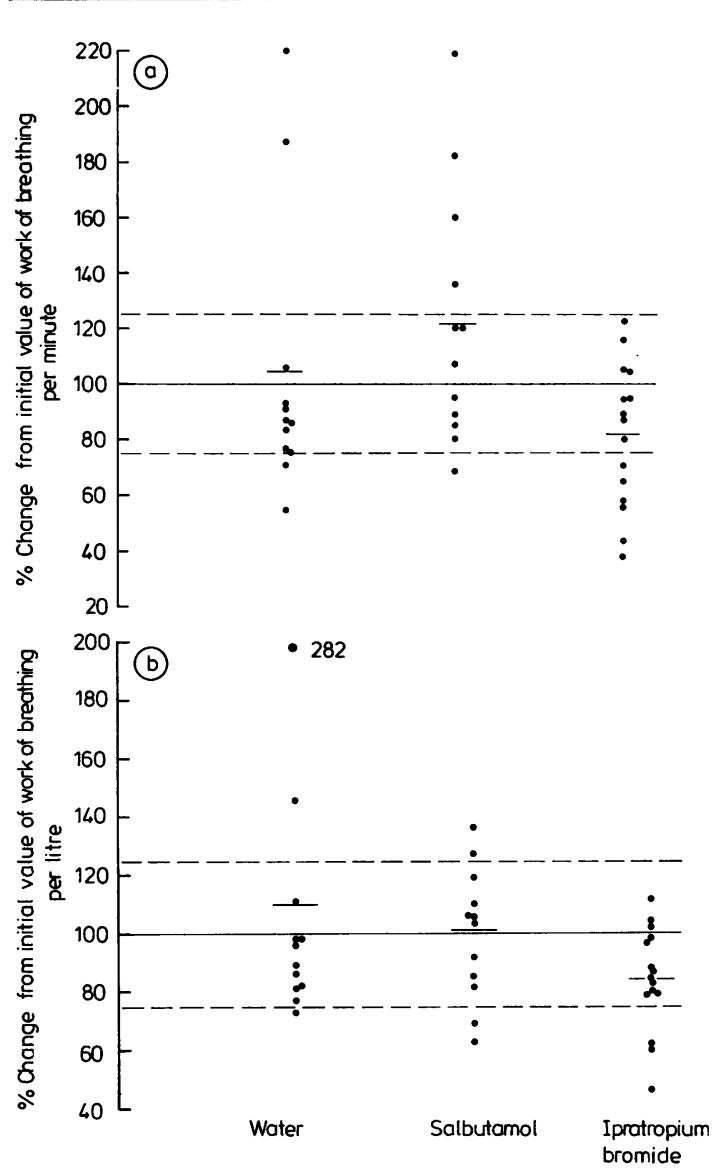

20 minutes after inhalation of nebulised therapy

Fig. 2 Changes in total work of breathing (a) per minute, (b) per litre, 20 minutes after nebulised water, salbutamol, and ipratropium bromide.

Table 1 Patients showing improvement or deterioration in work of breathing results

\begin{tabular}{|c|c|c|c|c|c|c|}
\hline & \multirow{2}{*}{\multicolumn{2}{|c|}{$\begin{array}{l}\text { Mean change expressed } \\
\text { as } \% \text { of initial }\end{array}$}} & \multicolumn{4}{|c|}{ Infants showing $>25 \%$} \\
\hline & & & \multicolumn{2}{|c|}{ Improvement } & \multicolumn{2}{|c|}{ Deterioration } \\
\hline & Per min & Per litre & Per min & Per litre & Per min & Per litre \\
\hline $\begin{array}{l}\text { Water }(n=12) \\
\text { Salbutamol }(n=12) \\
\text { Iprat ropium bromide }(n=15)\end{array}$ & $\begin{array}{r}104 \cdot 4 \\
121 \cdot 8 \\
81 \cdot 8\end{array}$ & $\begin{array}{l}110 \\
100 \cdot 5 \\
84\end{array}$ & $\begin{array}{l}2 \\
1 \\
6\end{array}$ & $\begin{array}{l}1 \\
2 \\
3\end{array}$ & $\begin{array}{l}2 \\
4 \\
0\end{array}$ & $\begin{array}{l}3 \\
2 \\
0\end{array}$ \\
\hline
\end{tabular}


The group $t$ test was used to compare the baseline and 20 minute post-therapy results. This showed that the improvement in the work of breathing per minute was significant at the $2.5 \%$ level and work of breathing per litre at $1 \%$. The deterioration after water and salbutamol did not reach statistical significance.

\section{Discussion}

Many children who have acute bronchiolitis in early infancy subsequently have recurrent wheezing attacks and merge with the asthmatic population. For this reason bronchodilator drugs have been tried for many years. Several studies have failed to show any benefit from a wide range of drugs, but all have been carried out in the convalescent phase on the assumption that a pattern of response at this stage will mimic that seen in the acute phase. However, many units still give bronchodilator drugs to the critically ill child with bronchiolitis and claim to see an improvement.

We have set out to look at these drugs objectively, measuring total work of breathing before and after the inhalation. The initial results of work of breathing were high, about 4 times the expected. ${ }^{9}$

Clinical management problems and the need for the studies to be carried out in quiet sleep prevented us from studying all the children against all the treatments. The same constraints prevented us from carrying out numerous recordings after treatment. On average the babies took 15 minutes to return to quiet sleep after the nebuliser treatment. Nevertheless these findings are of considerable interest. A change in work of breathing of more than $25 \%$ was chosen as this represents the $95 \%$ confidence limits of repeated measurements in quiet sleep.

Although in the group as a whole, water produced no change in work of breathing per minute, there was a $10 \%$ rise in work per litre, indicating that lung mechanics had deteriorated. Conversely, after salbutamol no change was seen in work of breathing per litre, but there was a $21.8 \%$ increase in work per minute, due mainly to an increase in minute volume. The coughing experienced by 6 babies during the inhalation of salbutamol was troublesome, a phenomenon not seen with either ipratropium bromide or water. It is possible that the irritant effect of salbutamol was responsible for the increase in minute volume.

Ipratropium bromide produced in 3 infants a larger than $25 \%$ fall both in work of breathing per minute and per litre, signifying an improvement in lung mechanics. In a further 3 infants, a reduction in minute volume was the predominant factor in the significant fall in work of breathing per minute Four of the 6 babies whose work of breathing per minute decreased by more than $25 \%$ showed a greater than $40 \%$ change, which was associated with clinical improvement.

This study indicates that ipratropium bromide does sometimes reduce airways obstruction in acute bronchiolitis. We are currently assessing whether $250 \mu \mathrm{g}$ of the drug, given as a nebulised solution 6-hourly, has any effect on the natural history compared with nebulised saline.

We thank the parents who allowed us to study their babies, and their consultants, Professor D Hull, Dr P Barbor, Dr D I Johnston, and Dr N Rutter.

Financial assistance was provided by the Asthma Research Council, Boehringer Ingelheim, and Nestles' Paediatric Fellowship (Australia).

\section{References}

1 Phelan P D, Williams H E. Sympathomimetic drugs in acute viral bronchiolitis. Their effect on pulmonary resistance. Pediatrics 1969; 44: 493-7.

2 Rutter N, Milner A D, Hillier E J. Effect of bronchodilators on respiratory resistance in infants and young children with bronchiolitis and wheezy bronchitis. Arch Dis Child 1975; 50: 719-22.

${ }^{3}$ Lenney W, Milner A D. Alpha and Beta adrenergic stimulants in bronchiolitis and wheezy bronchitis in children under 18 months of age. Arch Dis Child 1978; 53: 707-9.

4 Field C M B, Connolly J H, Murtagh G, Slattery C M, Turkington E G. Antibiotic treatment of epidemic bronchiolitis-a double blind trial. $\mathrm{Br} \mathrm{Med} J$ 1966; i: 83-5.

5 Connolly J H, Field C M B, Glasgow J F T, Slattery C M, MacLynn D M. A double blind trial of prednisolone in epidemic bronchiolitis due to respiratory syncytial virus. Acta Paediatr Scand 1969; 58: 116-20.

6 Leer J A, Jr, Green J L, Heimlich E M, et al. Corticosteroid treatment in bronchiolitis. A controlled collaborative study in 297 infants and children. Am J Dis Child 1969; 117: 495-503.

7 Brooks L J, Cropp G J A. Theophylline therapy in bronchiolitis. Am J Dis Child 1981 ; 135: 934-6.

8 Stokes G M, Milner A D, Johnson F, Hodges I G C, Groggins R C. Measurement of work of breathing in infancy. Pediatr Res $1981 ; 15: 22-7$.

9 Stokes G M, Milner A D, Groggins R C. Work of breathing, intra-thoracic pressure, and clinical findings in a group of babies with bronchiolitis. Acta Paediatr Scand 1981; 70: 689-94.

10 Groggins R C, Milner A D, Stokes G M. Bronchodilator effects of clemastine, ipratropium bromide, and salbutamol in pre-school children with asthma. Arch Dis Child 1981; 56: 342-4.

11 Hodges I G C, Groggins R C, Milner A D, Stokes G M. Bronchodilator effect of inhaled ipratropium bromide in wheezy toddlers. Arch Dis Child 1981; 56: 729-32.

Correspondence to Professor A D Milner, Department of Child Health, Queen's Medical Centre, Nottingham NG7 2UH.

Received 17 December 1982 